\title{
Patrimônio natural e cultural do município de São Francisco de Itabapoana - Estado do Rio de Janeiro
}

\section{Suellen Siqueira Moraes}

Universidade Estadual do Norte Fluminense

suellen_siq@hotmail.com

\section{Mirian Alves Viana}

Universidade Estadual do Norte Fluminense miniva@gmail.com

\section{Maria da Glória Alves}

Universidade Estadual do Norte Fluminense mgloria@hotmail.com

\section{Resumo}

O presente trabalho tem como objetivo conscientizar o município de São Francisco de Itabapoana, localizado na Região Norte Fluminense do Estado do Rio de Janeiro, da importância dos bens patrimoniais existentes em sua região e estimular sua salvaguarda, pois tal município possui um expressivo acervo, destacando seus valores geológicos, arqueológicos, paisagísticos, ecológicos, climáticos e um rico histórico cultural. Os patrimônios são símbolos de um passado vivo, legado que sustenta os indivíduos em uma evolução permanente. Partindo de uma gama de informações adquiridas através dos pesquisadores da Universidade Estadual do Norte Fluminense (UENF), a metodologia abordada para a realização da pesquisa foi: levantamento de campo, cadastramento de pontos georreferenciados, entrevistas e longas conversas com os moradores de São Francisco. Como resultado pode-se citar o material elaborado a partir dos dados descritos acima, compondo um livro/atlas com textos informativos, fotos e mapas de localização dos patrimônios naturais e culturais do município. Enfim, durante a realização do projeto, que se estendeu por três anos, de 2009 a 2011, percebeu-se que a finalidade do trabalho foi alcançada, pois atualmente São Francisco de Itabapoana tem um olhar diferente para seus patrimônios e descobriu que investir na preservação de seus bens culturais e naturais traz benefícios para a população, para a economia do município e ainda gera ações que protegem seus patrimônios.

Palavras-chave: Preservação dos bens patrimoniais. Patrimônios naturais e culturais. São Francisco de Itabapoana-RJ. 


\title{
Natural and cultural heritage of the city of San Francisco de Itabapoana - State of Rio de Janeiro
}

\begin{abstract}
This paper aims to educate the São Francisco de Itabapoana located in the Região Norte Fluminense State of Rio de Janeiro of the importance of the property existing in your area and encourage its preservation. Well this has a significant collection, highlighting their values geological, archaeological, landscape, eco-logical, climate and a rich cultural history. The assets are symbols of a living past, a legacy that sustains individuals in a permanent evolution. From a range of information acquired through the Universidade Estadual do Norte Fluminense (UENF), addressed the methodology for the research was a field survey, registration of georeferenced points, interviews and long conversations with the residents of São Francisco. As a result one can cite material drawn from the data described above, composing a book/atlas with informative texts, photos and location maps natural and cultural heritage of the city. Anyway, during the course of the project which lasted for three years going from 2009 to 2011, it was realized that the purpose of the study was achieved. Well, now São Francisco de Itabapoana has a different look to their assets and discovered that investing in the preservation of their cultural and natural benefits for the population, for the economy of the city and still generates actions that protecting their assets.
\end{abstract}

Keywords: Preservation of the property. Natural and cultural heritage. São Francisco de Itabapoana - RJ.

\section{INTRODUÇÃO}

Localizado no litoral da Região Norte Fluminense, a 368 km da capital Rio de Janeiro (RJ), São Francisco do Itabapoana é o segundo maior município do Estado em extensão territorial, com $1.111,335 \mathrm{~km}^{2}$, e tem uma população estimada em 41.357 habitantes (IBGE, 2010). São Francisco é dono de um proeminente patrimônio natural e cultural, como valores geológicos, geomorfológicos, climáticos, paisagísticos, ecológicos e culturais.

A beleza do município tem um significativo potencial histórico com sua arquitetura colonial, seus grandes latifúndios com casarões da época da escravidão, suas atividades artesanais - tradição passada de geração em geração com as fabriquetas de farinhas -, suas danças com descendência afro-brasileira, portuguesa, indígena e um costume tipicamente colonial (ALVES, 2008). Também existem locais de importância arqueológica com fortes indícios de serem cemitérios escravos. 
No patrimônio natural, destacam-se as praias que juntas somam mais ou menos $60 \mathrm{~km}$ de belos cenários, águas tranquilas e temperaturas sempre amenas. Seus manguezais são uma opção de lazer à parte, sendo um dos ecossistemas mais rico e maior da zona costeira do Estado. $\mathrm{O}$ município também é beneficiado por sua formação geológica composta por rochas que vão do Pré-Cambriano ao Quaternário (COELHO, 2010).

Porém, a preocupação com a salvaguarda dos patrimônios não é algo recente, vinda com a modernidade. Os bens patrimoniais são fatores importantes no desenvolvimento de uma sociedade, principalmente quando ele acarreta signos que vão além de sua história local.

Segundo Peter Burke (1999), esse movimento começou no final do século XVIII agregando à noção de herança cultural o registro de algumas histórias populares da classe mais baixa. Os estudiosos começaram a perceber que essas tradições eram o que diferenciavam um grupo ou uma nação. Burke aponta uma ampliação no conceito com o tempo, agora cultura se refere a tudo que pode ser referência de uma comunidade: seu modo de comer, de andar, de falar, suas habilidades.

A importância da transmissão desses elementos, seus espaços, suas festas, suas lembranças é que enraíza a memória das comunidades. Suas ruas, seu sotaque, suas paisagens são símbolos de um passado vivo, conduzido por grupos aptos às transformações e a uma evolução permanente. Esse é o verdadeiro conceito de patrimônio para Pierre Nora (1993), projetado simbolicamente para dar vida e sentidos aos ambientes que marcam presença e reforçam as descrições locais.

Os patrimônios fazem referência às representações de uma comunidade, e tantos os bens naturais quantos os culturais não devem estar dissociados das narrativas locais, pois estes são fonte de riquezas morais, sociais e culturais. Os patrimônios contam a história do nosso passado; portanto, torna-se necessário preservar as paisagens, as lendas, as festas, pois são vestígios da história de existência da Terra. Seus valores, práticas e crenças são resultados da interação entre homem e o espaço.

Assim, São Francisco do Itabapoana dispõe de um rico acervo patrimonial, mas que infelizmente não recebe uma política apropriada para a preservação ou valorização de suas riquezas, tanto naturais quanto culturais. Por essa razão, o projeto tem por objetivo conscientizar a sociedade sanfranciscana em relação aos seus patrimônios, para que ela possa agir preservando os ambientes patrimoniais de sua região.

Esta obra está licenciada sob uma Licença Creative Commons. 
Promover o conhecimento e estimular a cidadania dos indivíduos é função das instituições de ensino, e a Universidade Estadual do Norte Fluminense (UENF) foi criada com o propósito de levar suas ciências para além de seus muros, contribuindo para a formação de agentes para a disseminação do conhecimento na Região Norte Fluminense.

A Pró-Reitoria de Extensão e Assuntos Comunitários (PROEX), em seu universo de atuação, apoio, elaboração e financiamento de projetos, tem disponibilizado todos os esforços e recursos para que a UENF desempenhe o papel que lhe foi conferido: a promoção do desenvolvimento regional.

\section{MATERIAL E MÉTODOS}

Para a realização desta pesquisa, partiu-se de duas abordagens: a primeira para coleta de dados históricos de São Francisco e a segunda para organização e elaboração dos resultados.

A primeira etapa voltou-se para a organização dos dados históricos do município, pois São Francisco de Itabapoana possuiu muito pouca bibliografia. Devido a esse fato, foram elaboradas:

1 - Visitas realizadas pelos bolsistas do projeto de extensão junto ao professor responsável ao município de São Francisco do Itabapoana, para a descrição da história local, contada pelos próprios moradores, utilizando o método da história oral.

2 - Visitas também a arquivos públicos de municípios vizinhos, como Campos dos Goytacazes e São João da Barra (antiga sede de São Francisco), e à Biblioteca Nacional na cidade do Rio de Janeiro, onde existe um grande número de documentos referentes à formação de São Francisco.

Com a aquisição dos dados através das duas fontes citadas acima, conseguiu-se chegar a pontos comuns dos relatos e organizar um cronograma histórico de São Francisco.

O segundo momento da pesquisa seria então o cadastramento dos pontos importantes de patrimônios, tanto naturais quanto culturais do município, para assim concluirmos os mapas, o banco de imagem e os demais dados. Para essa etapa, os alunos envolvidos na pesquisa utilizaram a seguinte metodologia:

- Levantamento de campo com o uso de um GPS para georreferenciar os pontos visitados, 
de uma câmera fotográfica e uma filmadora para registrar os patrimônios.

- Laboratório - o trabalho dava-se em torno da criação dos textos informativos, da concepção dos mapas com base nos pontos georreferenciados e da compreensão das imagens.

- Divulgação - a pesquisa produziu um material de extrema importância para São Francisco, que está sendo divulgado por meio de instrumentos específicos, tais como: eventos (congressos, encontros científicos), jornais, televisão, revistas.

\section{RESULTADOS E ANÁLISE}

Em atendimento aos objetivos definidos para a pesquisa, obtiveram-se bons resultados. Apesar dos contratempos, devido à escassez de informação a respeito do município, direcionou-se o trabalho para outro viés, adotando metodologias eficazes para sua conclusão.

No mérito social e cultural do projeto, pretendia-se contribuir para a conscientização, em termos de patrimônio cultural e natural; propiciar à população local o uso de novos recursos e estimular a Educação Patrimonial como um meio de salvaguarda de seus patrimônios. Um fator que após iniciar-se a pesquisa pôde ser notado, pois antes havia um grande desconhecimento da sociedade em relação ao imenso patrimônio existente na região.

A pesquisa chamou atenção para os bens patrimoniais, valorizando o potencial que o São Francisco de Itabapoana possui. As visitas ao município foram muito produtivas, pois ao mesmo tempo em que se colhiam informações a respeito da história local, dava-se elementos para que os sanfranciscanos se identificassem como suas raízes, protegendo seus patrimônios culturais e naturais.

O projeto trouxe adições para o município, apresentando novas fontes de renda com o desenvolvimento do turismo ecológico, do turismo rural, pois, apesar de muito rico em recursos minerais e paisagísticos, ainda tem uma população muito carente de conhecimento e de empregos. O material produzido com a pesquisa poderá ser usado por educadores, gerenciadores do município e pela própria população, para realizar atividades de aulas, de educação ambiental, turismo (realização de visitas guiadas para grupos), como também ações de valorização ou de reabilitação para assegurar a proteção do patrimônio, evitando a destruição ou a ocupação urbana/industrial de áreas patrimoniais. 
O produto final resume-se em um livro/atlas, o qual contém:

- Introdução.

- Localização do município de São Francisco.

- Localização e definição dos patrimônios naturais e culturais.

- Textos informativos mostrando onde fica e como chegar a cada patrimônio.

- Texto subdividido em: Patrimônio Arquitetônico, Cultural, e Arqueológico, além dos patrimônios geológico, geomorfológico, ecológico, paisagístico e climático.

- Fotos e mapas dos patrimônios culturais e naturais.

O cronograma da pesquisa já foi encerrado no âmbito institucional, mas, para que o projeto seja completo, conta-se com o financiamento para as impressões do livro/atlas. Para que, enfim, a população tenha em mãos sua história, seus patrimônios reconhecidos para que de modo algum eles se percam.

\section{CONSIDERAÇÕES FINAIS}

Vale ressaltar que São Francisco do Itabapoana possui um amplo território, onde suas formações naturais e culturais mostram uma grande diversidade e beleza. A presente pesquisa permitiu à população de São Francisco de Itabapoana sentir-se sujeito de sua história, ajudando-nos e sendo parceiros em todas as etapas do projeto.

Hoje o município tem um documento que descreve sua importância, seus valores, seja na história, na economia ou no contexto social da Região Norte Fluminense. Este trabalho apresenta uma proposta inovadora e de grande importância para São Francisco, pois o material poderá ser divulgado em todo o território brasileiro e colaborará para a disseminação do conhecimento patrimonial, principalmente para a população local.

Dessa forma, pode-se dizer que a principal meta do projeto foi alcançada, pois os moradores de São Francisco de Itabapoana desenvolveram uma consciência ecológica e cultural. Seja por ambições econômicas, por aquisição de conhecimento ou ainda por identificação com seu habitat, a pesquisa ajudou a promover a ampliação de oportunidades, a facilitar o acesso à informação e a qualificar a população para que ela agisse mediante a tarefa de preservar os seus 
recursos patrimoniais.

\section{AGRADECIMENTOS}

Nossos sinceros agradecimentos a todos que, de forma direta ou indireta, contribuíram para a realização deste projeto. Agradecemos à Universidade Estadual do Norte Fluminense (UENF) e à Pró-Reitoria de Extensão e Assuntos Comunitários (PROEX) por possibilitarem nossas pesquisas.

\section{REFERENCIAS}

ALVES, Maria da Gloria; TEIXEIRA, Simonne. Patrimônio Natural e Cultural de Campos dos Goytacazes. Campos dos Goytacazes, EDUENF, 2008.

BURKE, Peter. A Cultura popular na Idade Moderna: Europa, 1500-1800, São Paulo, Companhia das Letras, 1989.

COELHO, Adilson Marcio. Utilização de geoprocessamento no planejamento do uso das terras para o desenvolvimento urbano do município de São Francisco de Itabapoana, RJ. 2008. Dissertação (Mestrado em Engenharia Civil)- Universidade Estadual do Norte Fluminense Darcy Riberio, Campos dos Goytacazes, RJ, 2008.

Instituto Brasileiro de Geografia e Estatística. IBGE Cidades. Disponível em:

$<$ http://www.ibge.gov.br/cidadesat/topwindow.htm?1>. Acesso em Setembro de 2012. 